\title{
EFL Teachers' Emotional Intelligence and Their Personality Types: Exploring Possible Relations
}

\author{
Roya Razavi \\ Department of Language and Humanities Education \\ Nabi Akram University,Tabriz,Iran \\ E-mail: razavi_r2002@yahoo.com
}

\author{
Doi:10.7575/aiac.alls.v.5n.2p.134 \\ URL: http://dx.doi.org/10.7575/aiac.alls.v.5n.2p.134
}

Received: 03/03/2014

Accepted: 09/04/2014

\begin{abstract}
The major aim of this study was to examine the relationship between teachers' emotional intelligence and their personality traits in an Iranian context. To this end, 85 Iranian EFL teachers were asked to fill out The Big Five Inventory Personality Test (John \& Srivastava, 1999) and The Bar-On Emotional Intelligences test (1997). The results showed both negative and positive correlations among different subscales of the variables under study. It was found that among the 15 components of EI, problem solving has the highest positive correlation with personality types (i.e., agreeableness). Also, problem solving was found to have the highest negative significant correlation with personality types (i.e., neuroticism). Pedagogical implications are discussed.
\end{abstract}

Keywords: EI, Personality types, EFL teachers

\section{Introduction}

As Horn and Noll (1994) put it, teachers play important roles in students' achievement and success in the classroom. Teachers are important effective agents in the classroom and their significant effect on education in general and ELT in particular have been studied from different perspectives and angles. The Qualities of a good teacher have been explored over the past fifty years (Barr et al., 1955; Long, 1957; Feldman, 1976; Gage, 1978; Soar et al., 1984; Barry and Rogers, 1985; Borich, 1986; Adams, 1987; Lombard and Bunting, 1989; Reid, 1999). What these studies have focused on has been the general idea of traits rather than the teachers' emotions. Only some of these studies have explored emotional variables such as Emotional Intelligence (EI), and some other variables related to teachers' general data processing and cognitive styles.

The concept of EI was first introduced by Peter Salovey and John, D. Mayer (1990) as a variable to help recognize that emotions in fact played a decisive role in Problem-Solving and adaptation in everyday life. Later, Goldman's (1995) book entitled "Emotional intelligence, why it can matter more than IQ" propelled the concept to get on the bad-wagon in the research arena. It should not go unmentioned that EI is understood in two general ways among researchers and those specialists in the field: First, as a restricted set of mental abilities involving the process of emotional information (Mayer, Salovey \& Caruso, 1997; Salovey and Mayer, 1990). And second, which is also the concern of the present study, puts EI as a set of personality traits, skills and abilities (Bar-on, 1997: Goldman, 1995) accessed through Selfreport or 360 degree evaluation model. (Bar-on, 1997).

Yet the concept of EI as a variable may not be that much practical in the teaching classroom with observable behavioral outcomes. Thus, it ought to be linked somehow to variables such as personality types among teachers or students.

Personality in general has been studied in several different levels with each trying to unfold new aspects of human behavior (John, Hampton and Goldberg, 1991; McAdams, 1995). One very important level has been that of Human traits. (Cosling and John, 1999). John and Strivastava (1999) propose four main personality types namely, introversion vs. extroversion, agreeableness vs. antagonism, and consciousness vs. lack of attention, neuroticism vs. emotional stability, and finally openness vs. closedness to experience.

The Big Five taxonomy offered by John and Srivastava (1999) is based on the following factors:

I. Extroversion or Surgency that is the extent to which a person is talkative, assertive and energetic.

II. Agreeableness which describes the extent to which a person is good natured cooperative and trustful.

III. Conscientiousness that is how a person is orderly, responsible and dependable.

IV. Emotional stability versus Neuroticism describing the nature of being calm, not neurotic and not being easily upset.

V. Finally Intellect and openness, which go to that intellectual, imaginative and independent-minded nature of people.

The above factors have also been employed by several researchers (Norman, 1963; Borgatta 1964; Digman and Takemoto-chock, 1981)

The purpose of the present study is to explore the relationship between EI and the Big Five Personality Types. 


\section{Review of the related Literature}

Though results from three studies done by Petrides et al. (2007) show that emotional intelligence might be an informative construct above and beyond personality and not affected by that, there existed various limitations to their studies .In the first two of the studies, Petrides et al. employed a recently developed scale called the Trait Emotional Intelligence Questionnaire (TEIQue) with two samples of participants $(n=166$ British college students and $n=354$ unspecified). They saw that the TEIQue was related to measures of rumination, life satisfaction, depression, along with dysfunctional attitudes and coping. However, the remaining associations between EI and the other variables were not rather high after accounting for the Five Factor Model of personality (FFM) variance, making the meaning of the associations questionable. In their third study, Petrides et al. demonstrated that trait EI might be the underlying factor that explains person's susceptibility to a great range of personality disorders. In that third study, Petrides et al. gave the TEIQue to college students in Spain $(n=212)$, as well as measures of personality disorders, depression, and dispositional (or "trait") mood. EI was significantly correlated with all of the variables of personality disorder, which are typically highly associated with personality disorders. This study suggests that low EI may be a basic risk factor for the development of serious mental health problems and not the result of mental health problems. However, these results were correlational and also obtained from a group of College students, so any interpretation from these results should be with caution.

Mayer and Cobb (2000) propose that the FFM personality model is by no means perfect, and in fact has been depicted to have very little relationship with job success in certain occupations (e.g., teachers), leaving an opportunity for EI to provide information in these areas. However, in a review of personality and EI, McCrae (2000) points out how each of the trait EI concepts overlaps with the FFM and shares some features.

On the other hand, though there is enough evidence showing that FFM is a cross-culturally valid theory of personality (McCrae \& Costa, 1999). This has direct implications for the use of trait EI measures (e.g. the ECI-U that was administered to Pacific's 2006 incoming freshmen class) because they were developed in a Western culture. Thus, persons in a culture with low norms for expressiveness may not rate items in a manner that is considered "emotionally intelligent" in a culture with norms of high expressiveness.

In the past years there have been numerous studies exploring the relationship between EI and demographic factors such sex and age, we summarize some of them below:

\subsection{EI and Age}

Generally in children the older they get, the greater their Emotional Competence will get. The studies have showed that EI increases with Age and grade. It has been put that emotional maturity was positively related with physiological maturity. Salovey and Mayer (1990) showed that EI increases with age and experience. Furthermore, in another study Goleman (1995) found that the signs of EI appear in young children.

Goleman (1996) have also stated that emotional intelligence increases with age and it can be learned, cultivated and increased in adulthood. In a series of longitudinal studies, it was shown that people can change their EI competencies over two to five years (Boyatzis, 2000).

Mayer et al. (2000) also showed with a series of studies that emotional intelligence increased with age and experience which qualifies it as ability rather than a personality trait. Wong and Law (2002) who replicated the study on a different group of subjects found that age is positively correlated with emotional intelligence in various job contexts.

Similarly, Kafetsios (2004) did a study on 239 adults who were aged between 19-66 years. He concluded in his study that older participants got higher scores on three out of four branches of EI which were facilitation, understanding and management. This study backs the idea that emotional intelligence increases with age.

In another study Srivastava and Bharamanaikar (2004) explored the relationship between age and EI among 291 Indian army officers. Their study also supported the idea that EI increases with age.

Tyagi (2004) did a study on secondary school language teachers in order to measure their EI level. In his study he found that there is not a significant relationship between EI and age as an independent variable.

Parker, Saklofske, Wood, Eastabrook \& Taylor, (2005) conducted a study aiming at finding where EI related abilities were stable during life transitions. They focused on the transition from high school to university in a period of 32 months. The study employed Bar-on (1997) 's test, and concluded that the overall change in the EI level of the participants was more than the level to be a result of the short time span and change in the age of the participants.

Van-Rooy, Alonso and Viswesvaran (2005) administered a common measure of EI to 275 participants a large majority of which were female (about 216) to examine how different age-groups scored on a test of EI. The results indicated that emotional intelligence scores tended to increase with age and that there was a positive correlation between the two variables, namely EI and age.

In order to get an account of EI in early and middle adulthood, Chapman and Hayslip (2006) made a cross-sectional analysis and explored if the age exerts a significant difference on EI.

In their study mid-life adults reported greater use of optimism (a component of emotional intelligence) as a mood regulation strategy compared to young adults.

Gowdhaman and Murugan (2009) conducted a study on 300 teacher trainees to explore the relationship between EI and age. The results of their study proved that age affects EI to a large extent. 


\subsection{EI and Gender}

Thingujam and Ram (2000) in their effort to get the Indian adaptation of Emotional Intelligence Scale (Schutte et al, 1998) developed Indian norms $(\mathrm{N}=811)$ for males and females separately and the results showed that gender affected their performance on the EI scale. Ciarrochi, Chan and Bajgar (2001) reached the idea that EI was reliably measured in adolescents and based on the results it was presumed that IE was higher for females than males. Other scholars who worked on the relationship between IE and age were Charbonneau and Nicol (2002). They conducted a six-week study in a military training camp by which they observed higher EI scores for girls, although the results were not statistically significant.

In order to observe EI levels of undergraduate male and female college students aged 17-20 years, Nasar (2008) conducted a study which rendered higher EI in the adolescent girls compared to the boys.

Brackett, Mayer and Warner (2004) reported in their study that women scored significantly higher in EI than men.

According to Uma Devi and Rayal's (2004) study (N=224) on gender differences and EI it was found that boys have scored higher than their girl counterparts (81 percent of boys as compare to the 76 percent of girls in their EI scores) .

Hunt and Evans (2004) studied individuals which had traumatic experiences and reported that males have higher EI than females. Furthermore, Carr's (2009) study among 177 medical students revealed that males score higher in EI test than females do.

In spite of the above findings, Kafetsios (2004) studied gender differences in Emotional Intelligence among 239 adults with the age 19-66 and using the Mayer, Salvony and Caruso Emotional Intelligence test (MSCEITV20) found that females' scores were higher than males' scores on both emotion perception and experimental area.

Another study in line with Kafetsios (2004) is the study done by Pandey and Tripathi (2004) with a sample of 100 individual (50 male, 50 female). It showed that females scared highly than males in Emotional intelligence test and females were reported to be more adept in managing and controlling their own emotions and those of others.

Studying on the 86 hetrosexual couples' EI ability, Beckett, Warner and Bosco (2005) found that females have higher Emotional Iintelligence scores than their male counterparts.

VanRooy, Alonso and Viswesvaran (2005) conducted a research with 275 participants and found that women scored slightly highly than males in EI test.

Austin, Evans, Gold water and Potter's (2006) study on Emotional Intelligence among 156 first year medical students revealed that females scored significantly higher than men.

Investigating the level of Emotional Intelligence among police constable trainees Jadhav and Havalappanavar (2009) found that Women Police Constable (WPC) trainees scored higher than men in EI test .The reason may be because women spend more life in home and with family while men tend to be more with peers. So women can better control their emotions. Of course it was found that Women Police Constable (WPC) had higher scores on emotional stability, altruism, empathy, self -motivation and self- awareness components of EI than men.

Pant and Prakash (2004) study of gender difference in Emotional Intelligence with 60 Indian participants and using multifactor Emotional Intelligence scale for assessing them revealed that there was no significant gender differences on the various EI sub-tasks of managing other emotions. Although in the sub-tasks 'managing other' the males $(\mathrm{M}=0.28$, $\mathrm{SD}=0.08)$ scored higher than females $(\mathrm{M}=0.26 / \mathrm{S} . \mathrm{D}=0.08)$. On the 'managing self ' sub-tasks they were same $(\mathrm{M}=0.25)$. Worth mentioning women scored slightly higher than men on total EI. But another study by Saranya and Velayudhan (1008) among 60 university students showed that there wasn't any significant difference in self-awareness, social awareness, self- regulation and social skills among boys and girls. The difference was in the amount of motivation. It was found that girls are more motivated than boys because of having more driving and pulling forces towards their goals.

Regarding gender difference and variables of emotional intelligence such as attribution, taking responsibility and scholastic achievement among high school students aged 13-17 years, Mathur, Malhotra and Dube (2005) found that there wasn't any significant difference between girls and boys on their EI variables.

The results of a research on participants' perceptions of own and parental psychometric intelligence(IQ) and emotional intelligence(EI) by Petrides, Furnham and Martin(2004) showed that people perceive psychometric intelligence to be primarily male-attributed while emotional intelligence is perceived to be more female-oriented. Of course this result may be altered when participants consider specific EI rather than overall self-estimate.

Another study examining culturally relevant variables like universal diverse, orientation and emotional intelligence and gender revealed that there was variance in empathy.

Singh Chaudhary and Asthana's (2008) study on gender differences and EI among 400 adolescents revealed that male and female adolescents represent some type of EI like giving, caring, enriching and supporting.

Gowdhaman and Murugan(2009) conducted a study on 300 teacher trainees and found that gender had a significant effect on EI scores.

In Iran, there are a number of studies which have investigated the correlation among teacher variables. For example, Safaree and Tarlani (2013) have indicated positive correspondences between the teacher's personality traits and their 
teaching reflection practices. Extrovert teachers, for instance, were found to draw on the affective elements in their teaching practices.

Given above, the purpose of the present paper is to investigate whether there are correlations between the teachers' EI and their personality types.

\section{Methodology}

\subsection{Participants}

85 Iranian EFL language teachers including 36 males (42.35\%) and 49 females (47.65\%) constituted the participants of the present study. They were all majoring in English language Teaching with varying years of experiences ranging from $5(14 \%), 6(24 \%), 7,(9 \%), 8(23 \%)$ to $9(30 \%)$ years in ELT. They were teaching in language institutes in Tehran, the capital city of Iran. They were asked to fill in the two questionnaires (see 3.2) at their convenience. They were allowed to take the questionnaires home. The researcher was in constant email (and in some occasions phone) correspondence with the teacher participants to respond to possible questions.

\subsection{Instruments}

The following instruments were used in the current study:

a. The Big Five Inventory Personality Test (John \& Srivastava, 1999)

b. The Bar-On Emotional Intelligences test (1997)

John \& Srivastava's (1999) the Big Five Inventory Personality Test is a 44-item questionnaire (on a five-lickert scale from "strongly disagree" to "strongly agree") which measures five different personality types: openness, extroversion, conscientiousness, agreeableness, and neuroticism. The Cronbach alpha values for each subscale's internal consistency were as follows in the present study: .78 (Conscientiousness), .73 (Neuroticism), .82 (Extraversion), .72 (Openness), and finally .81, (agreeableness).

With regard to EI test, 133 items comprised the questionnaire employing a 5-point scale ranging from 'very seldom' or 'not true of me' to 'very often' or 'true of me'. (see above for the sub-components of the questionnaire. The Cronbach alpha values for each subscale's internal consistency were as follows in the present study: .69 (Independence), .74 (Empathy), .85 (Interpersonal Relationship), .71 (Social responsibility), .86 (Impulse Control), .88 (Happiness), .89 (Optimism), .77 (Problem Solving), .77 (Reality Testing), .81 (Flexibility), .80 (Stress Tolerance), .89 (Emotional SelfAwareness), .76 (Assertiveness), .81 (Self-Regard), .82 (Self-Actualization).

\subsection{Procedures and Data analysis}

Credibility and feasibility of the language institutes were factors based on which we chose participants. Then, the participants were chosen and given the questionnaires to fill out. They were all explained. To diagnose the normality of the distribution, descriptive statistics was employed. As shown in Figure 1, the data are normal since the scores gather around the straight line. Thus, we are safe to use a Pearson product-moment correlation to determine whether the teacher's EI are correlated with their personality types.

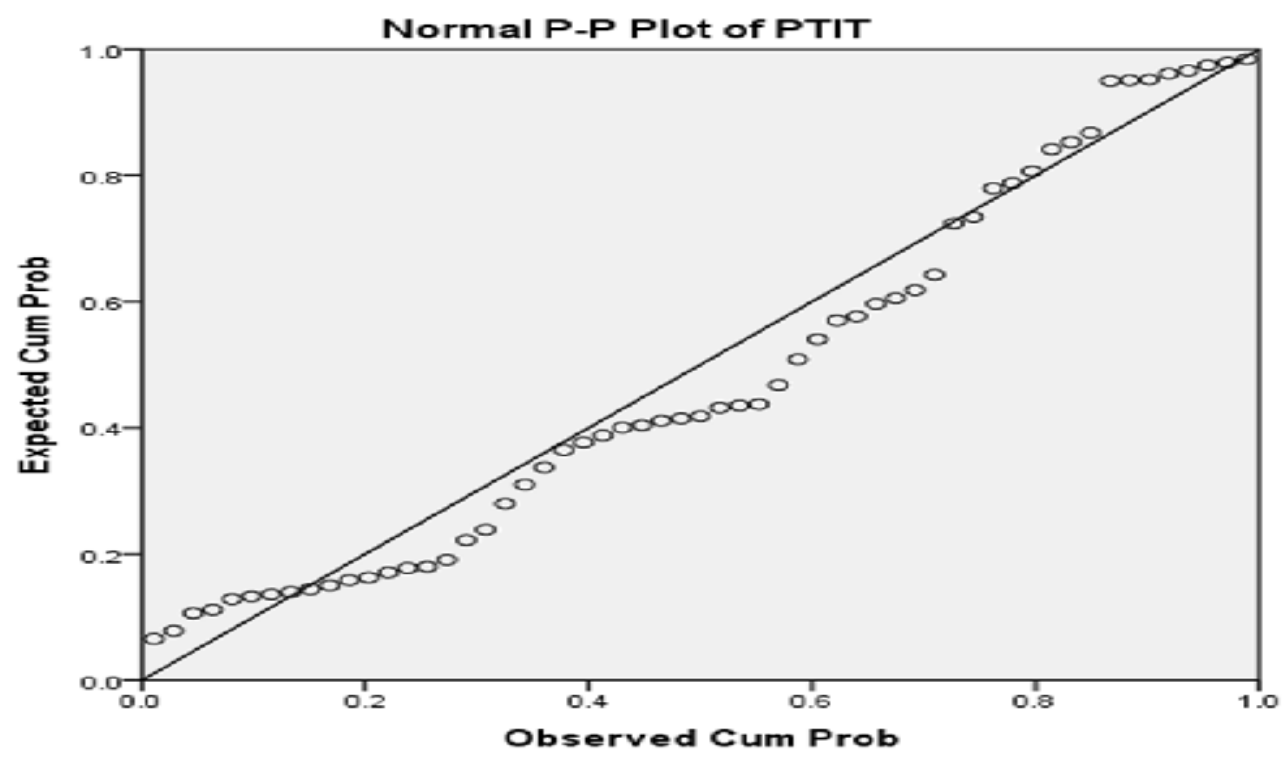

Figure 1. P-P plot for diagnosing normal distribution of data

\section{Results and discussion}

Table 1 shows correlations between the observed components of the EI and personality types. It was found that among the 15 components of EI, problem solving have the highest positive correlation with personality types (i.e., agreeableness). Also, problem solving was found to have the highest negative significant correlation with personality 
types (i.e., neuroticism). To begin with, there is a positive and significant relation between independence and openness. Empathy is positively correlated with both agreeableness and openness at .01. However, mixed results were found with reference to the correlations between interpersonal relationship with agreeableness, neuroticism and openness. We found that interpersonal relationship is negatively correlated with agreeableness. In contrast, it was positively related to neuroticism and openness.

Table 1. Correlations among Construct Variables

\begin{tabular}{|c|c|c|c|c|c|}
\hline EI Personality & Extroversion & Agreeableness & Conscientiousness & Neuroticism & Openness \\
\hline Independence & -.106 & .178 & .143 & -.250 & $.320^{*}$ \\
\hline Empathy & $.448^{* *}$ & -.211 & .032 & .147 & $.250^{* *}$ \\
\hline $\begin{array}{l}\text { Interpersonal } \\
\text { Relationship }\end{array}$ & .115 & $-.385^{* *}$ & -.214 & $.484^{* *}$ & $.392^{* *}$ \\
\hline $\begin{array}{l}\text { Social } \\
\text { responsibility }\end{array}$ & .198 & $-.603^{* *}$ & $.667^{* *}$ & $-.635^{* *}$ & $.310^{*}$ \\
\hline Impulse Control & $-.413^{* *}$ & .142 & .022 & $-.273^{* *}$ & .010 \\
\hline Happiness & .051 & -.023 & -.102 & .156 & $.315^{*}$ \\
\hline Optimism & $.464^{* *}$ & $.314^{*}$ & .257 & -.202 & $.463^{* *}$ \\
\hline Problem Solving & .148 & $.830^{* *}$ & $.632^{*}$ & $-.767^{* *}$ & .257 \\
\hline Reality Testing & -.137 & $-.497^{* *}$ & $-.434^{* *}$ & .121 & -.116 \\
\hline Flexibility & -.112 & $-.587^{* *}$ & $-.561^{* *}$ & .177 & -.083 \\
\hline Stress Tolerance & $-.346^{* *}$ & $-.451^{* *}$ & $-.391^{* *}$ & $.560^{* *}$ & $-.289^{*}$ \\
\hline $\begin{array}{ll}\text { Emotional } & \text { Self- } \\
\text { Awareness } & \end{array}$ & $-.546^{* *}$ & -.103 & $-.452^{* *}$ & .055 & -.124 \\
\hline Assertiveness & -.037 & $.261^{*}$ & .100 & .041 & -.114 \\
\hline Self-Regard & $-.493^{* *}$ & $-.532^{* *}$ & $-.636^{* *}$ & $.651^{* *}$ & $-.427^{* *}$ \\
\hline Self-Actualization & $-.632^{* *}$ & -.015 & -.104 & .065 & -.258 \\
\hline
\end{tabular}

** Correlation is Significant at the 0.01 Level (2-tailed)

${ }^{*}$ Correlation is Significant at the 0.05 level (2-tailed)

Social responsibility which is the ability to demonstrate oneself as a cooperative, contributing and constructive member of one's social group was negatively correlated with agreeableness. However, we found positive correlations between Social responsibility and conscientiousness, neuroticism, and openness. Impulse control which is the ability to control one's emotions and resist an impulse to act was negatively correlated with both extroversion and neuroticism. However, happiness was only correlated with openness in a positive way. One reason is that teachers might found themselves happy and feeling satisfied with life in being open to a strong intellectual curiosity and a preference for novelty and variety. Optimism was found to be positively correlated with extroversion, openness and agreeableness. When one is optimistic about the ongoing statuses of the affairs and has the ability to look at the brighter side of life and maintain a positive attitude in the face of problems is also extrovert (that is they have a higher degree of sociability, assertiveness, and talkativeness) and open to novelty and variety and is ready to be helpful, cooperative, and sympathetic towards others.

Problem solving was found to be positively related with agreeableness and conscientiousness but negatively with neuroticism. The reason is that, as research shows people can solve effectively a problem (for example in the case of teacher who has a student difficult to deal with) by having a cooperation, seeking their colleagues' sympathy and also by being disciplined, organized, and achievement-oriented. However, those who are emotionally instable, controlled in an impulse way and anxious are not capable enough to effectively solve problems.

Reality testing was found to be negatively correlated with agreeableness and conscientiousness. We argue that those who have the ability to validate their feelings and thoughts by assessing the correspondence between what is subjectively experienced and what objectively exists do not believe in seeking cooperation and are sympathetic towards others for the reason that they keep constantly validating their feelings and thoughts with world outside rather than being engaged in social cooperation. 
Also flexibility was found to be negatively correlated with agreeableness and conscientiousness. The result was in contrast with the general idea that those who have the ability to adjust their feelings and thoughts to change are cooperative and sympathetic towards others and also they are disciplined, organized, and achievement-oriented.

Stress tolerance which requires the ability to manage one's strong emotions, adverse events, and stressful conditions by positively coping with problems was found to be negatively correlated with extroversion, agreeableness and conscientiousness.

Emotional self-awareness that is the ability to be aware of, recognize and understand one's emotions was found to be negatively correlated with extroversion and conscientiousness. Assertiveness that is the ability to express one's feelings, beliefs, and thoughts to defend one's right was positively correlated with agreeableness. Self-regard, the ability to be aware of, understand, accept and respect oneself, was found to be correlated negatively with extroversion, openness, agreeableness and conscientiousness. However, it was observed to be positively correlated with neuroticism. And finally, self-actualization, the ability to realize and reach one's potential, was negatively correlated with only extroversion which is achieved through a higher degree of sociability, assertiveness, and talkativeness.

\section{Conclusion and pedagogical implications}

To sum up, the present study yielded a number of linkages among the observed components of the EI and personality types. The implication is that teachers characteristics that they actually bring with themselves to the classroom can potentially be employed to improve students' final achievements. In other words, if teachers are identified with possessing particular personality types and aligned their preferred emotional intelligences, this, no doubt, will affect their teaching behaviours in the class and this will in turn enhance their students' success. Also, of importance is the teacher training courses specifically designed for training teachers in particular areas focusing on skills associated with EI. Bar-on (2000) argues that EI develops over time and can be improved through training, programming, and therapy. According to Mafian and Ghanizadeh (2009), these courses should help them manipulate their emotions appropriately, shift undesirable emotional states to more productive ones, understand the link between emotions, thoughts and actions, attract and sustain rewarding interpersonal relationships in the classroom, and be sensitive to students' emotions. They point out encouraging and assisting teachers to gauge, manipulate, and improve their emotional stands, create greater student satisfaction with teachers and schools.

Since, to the best knowledge of the researcher, this is the first study in an Iranian context to examine the correlation between the teachers' emotional intelligences and their personality types, the results should be generalized with caution. The researcher suggests that other studies are needed to replicate the present study with similar teacher participants to see if the same results are achieved. Moreover, the current study brought to attention the importance of some other variables than we investigated in this study. For example, the gender and teaching experiences of the teacher participants were not taken in to consideration. Therefore, it warrants another future study to add these variables to the ones investigated here and discover whether these variables are also influential in teachers' preferences for particular personality types and emotional intelligences.

\section{References}

Adams, R. (1970). Duration and Incident Frequencies as Observation Indices. Education and Psychological Measurement, 30(3), 669-674.

Austin, E. J., Evans, P., Goldwater, R., \& Potter, V. (2005). A preliminary study of emotional intelligence, empathy and exam performance in first year medical students. Personality and

Individual Differences, 39, 1395-1405.

Bar-On, R. (1997a). Development of the Bar-On EQ-I: A Measure of Emotional Intelligence.

Paper presented at the 105th Annual Convention of the American Psychological Association, Chicago, August.

Bar-On, R. (1997b). The emotional quotient inventory (EQ-i). Technical manual. Toronto,

Canada: Multi-Health Systems.

Barr, A. S., Eustice, D. E. and Noe, E. J. (1955) the Measurement and Prediction of Teacher Efficiency. Review of Educational Research. 25(3), 261-269.

Barry, M. L. and Rogers, J. L. (1985). Dimensions Underlying Student Ratings of Instruction: a multidimensional scaling analysis. American Educational Research Journal. 22(2), 267-272.

Borgatta, E. F. (1964). The structure of personality characteristics. Behavioral Science, 9(1), 8-17.

Boyatzis, R. E., Goleman, D., \& Rhee, K. (2000). Clustering competence in emotional intelligence: Insights from the Emotional Competence Inventory (ECI). Handbook of emotional intelligence, 343-362.

Brackett, M. A., Mayer, J. D., \& Warner, R. M. (2004). Emotional intelligence and its relation to everyday behaviour. Personality and Individual differences, 36(6), 1387-1402.

Brackett, M. A., Warner, R. M., \& Bosco, J. S. (2005). Emotional intelligence and relationship quality among couples. Personal Relationships, 12(2), 197-212.

Cage, N. L. (1963). Handbook of research on teaching. Chicago: Rand McNally. 
Carr, S. E. (2009). Emotional intelligence in medical students: does it correlate with selection measures?. Medical education. 43(11), 1069-1077.

Chapman, B. P., \& Hayslip Jr, B. (2006). Emotional intelligence in young and middle adulthood: Cross-sectional analysis of latent structure and means. Psychology and aging, 21(2), 411-418.

Charbonneau, D., \& Nicol, A. A. (2002). Emotional intelligence and prosocial behaviors in adolescents. Psychological Reports, 90(2), 361-370.

Ciarrochi, J., Chan, A. Y., \& Bajgar, J. (2001). Measuring emotional intelligence in adolescents. Personality and individual differences, 31(7), 1105-1119.

Devi, U. and Rayal, (2004). Adolescent's perception about family environment and Emotional intelligence. Indian Psychological Review. 62(3),157-167.

Digman, J. M., \& Takemoto-Chock, N. K. (1981). Factors in the natural language of personality: Re-analysis, comparison, and interpretation of six major studies. Multivariate behavioral research. 16(2), 149-170.

Feldman, K. A. (1976). The Superior College Teacher from the Student's View. Research in Higher Education. 5(3), 243-288.

Gage N. L. (1978). The Scientific Basis of the Art of Teaching. New York: Teachers College Press.

Goldman, D. (1995). Emotional Intelligence. New York: Bantam.

Goleman, D. (1996). Emotional intelligence. Learning, 24(6), 48-67.

Gosling, S. D., \& John, O. P. (1999). Personality Dimensions in Nonhuman Animals A Cross-Species Review. Current Directions in Psychological Science, 8(3), 69-75.

Gowdhaman, K. \& Murugan, M.B. (2009). Emotional intelligence among the B.Ed. teacher trainees. Psycho-lingua. 187-190.

Horn, J. L., \& Noll, J. (1994). System for understanding cognitive capabilities: A theory and the evidence on which it is based. In D. K. Detterman (Ed.), Current topic in human intelligence. Volume IV (pp. 151-203). New York: SpringerVerlag.

Hunt, N., \& Evans, D. (2004). Predicting traumatic stress using emotional intelligence. Behaviour Research and Therapy, 42(7), 791-798.

John, O. P. \& Srivastava, S. (1999). The Big Five trait taxonomy: History, measurement, and theoretical perspectives. Handbook of personality: Theory and research, 2, 102-138.

John, O. P., Hampson, S. E., \& Goldberg, L. R. (1991). The basic level in personality-trait hierarchies: studies of trait use and accessibility in different contexts. Journal of Personality and Social Psychology, 60(3), 348.

Kafetsios, K. (2004). Attachment and emotional intelligence abilities across the life course. Personality and Individual Differences, 37(1), 129-145.

Lombard, M. J. \& Bunting, B. P. (1989). Teachers' Views on Methods of Appraisal. Educational Research 31(2), $150-$ 153.

Long, Sr M. B. (1957). A Synthesis of Recent Research Studies on Predicting Teaching Efficiency. Catholic Educational Review. 55, 217-231.

Mayer, J. D., \& Cobb, C. D. (2000). Educational policy on emotional intelligence: Does it make sense?. Educational Psychology Review, 12(2), 163-183.

Mayer, J. D., Caruso, D. R., \& Salovey, P. (2000). Selecting a measure of emotional intelligence. In R. Bar-On, \& J. D. A. Parker (Eds.), Handbook of emotional intelligence(pp. 320-342). San Francisco: Jossey-Bass.

Mayer, J. D., Caruso, D. R., \& Salovey, P. (1999). Emotional intelligence meets traditional standards for an intelligence. Intelligence, 27(4), 267-298.

McAdams, D. P. (1995). What do we know when we know a person?. Journal of personality, 63(3), 365-396.

McCrae, R. R. (Ed.). (2000). Personality traits and culture: New perspectives on some classic issues [Special issue]. American Behavioral Scientist,44(1), 10-31.

McCrae, R. R., \& Costa Jr, P. T. (1999). A five-factor theory of personality. Handbook of personality: Theory and research, 2, 139-153.

Moafian, F. \& Ghanizadeh. A. (2009). The relationship between Iranian EFL teachers' emotional intelligence and their self-efficacy in Language Institutes. System 37, 708718.

Nasar, J. L. (2008). Assessing perceptions of environments for active living. American journal of preventive medicine, 34(4), 357-363.

Norman, W. T. (1963). Toward an adequate taxonomy of personality attributes: Replicated factor structure in peer nomination personality ratings. The Journal of Abnormal and Social Psychology, 66(6), 574-589.

Pandey, R., \& Tripathi, A. N. (2004). Development of emotional intelligence: Some preliminary observations. Psychological Studies-University Of Calicut, 49, 147-150. 
Parker, J. D. A., Saklofske, D. H., Wood, L. M., Eastabrook, J. M., \& Taylor, R. N. (2005). Stability and change in emotional intelligence: Exploring the transition to young adulthood. Journal of Individual Differences, 26, 100-106.

Petrides, K. V., Pita, R., \& Kokkinaki, F. (2007). The location of trait emotional intelligence in personality factor space. British Journal of Psychology, 98(2), 273-289.

Reid, J. (1999). Improving Teaching in Higher Education: student and teacher perspectives Educational Studies. 25(3), 269-282.

Safaree, M \& Tarlani, H. (2013). Who practices what? A correlational study of personality type and teaching reflection. Presented at International Conference on Current Trends in ELT: Putting the Learner in the spot light. Urmia, Iran.

Salovey, P., \& Mayer, J. D. (1990). Emotional intelligence. Imagination, cognition and personality, 9, 185-211.

Schutte, N. S., Malouff, J. M., Hall, L. E., Haggerty, D. J., Cooper, J. T., Golden, C. J., \& Dornheim, L. (1998). Development and validation of a measure of emotional intelligence. Personality and Individual Differences, 25, 167177.

Soar, R. S., Medley, D. M., and Coker H. (1984). Teacher Evaluation: a critique of current methods. The Education Digest. 50(1), 44-47.

Srivastava, K. B., \& Bharamanaikar, S. R. (2004). Emotional intelligence and effective-leadership behaviour. Psychological Studies. 49(2-3), 107-113.

Thingujam, N. K. S., \& Ram, U. (2000). Emotional intelligence scale: Indian norms. Journal of Education and Psychology, 58, 40-48.

Tyagi, S. K. (2004). Emotional intelligence of secondary teachers in relation to gender and age. Journal of Educational Research and Extension, 41(3), 39-45.

Van Rooy, D. L., Alonso, A., \& Viswesvaran, C. (2005). Group differences in emotional intelligence scores: Theoretical and practical implications. Personality and Individual Differences, 38(3), 689-700. 